\title{
A Unique Palindromic Element Mediates Gamma Interferon Induction of mig Gene Expression
}

\author{
PHILIP WONG, ${ }^{1}$ CHRISTOPHER W. SEVERNS, ${ }^{1}$ NANETTE B. GUYER, ${ }^{1}$ AND \\ TIMOTHY M. WRIGHT ${ }^{1,2,3 *}$
}

Division of Rheumatology and Clinical Immunology, Department of Medicine, ${ }^{1}$ Department of Molecular Genetics and Biochemistry, ${ }^{2}$ and Pittsburgh Cancer Institute, ${ }^{3}$ University of Pittsburgh School of Medicine, Pittsburgh, Pennsylvania 15261

Received 20 August 1993/Returned for modification 25 September 1993/Accepted 5 November 1993

To define the molecular mechanisms involved in the action of gamma interferon (IFN- $\gamma$ ), we have analyzed the transcriptional regulation of the mig (monokine induced by gamma interferon) gene, a member of the platelet factor 4-interleukin-8 cytokine family that is expressed in murine macrophages specifically in response to IFN- $\gamma$. Analysis of mig/CAT chimeric constructs transiently transfected into the RAW 264.7 mouse monocytic cell line revealed a unique IFN- $\gamma$-responsive element $(\gamma \mathrm{RE}-1)$. The sequence of this cis regulatory element defined by deletion analysis contains an imperfect inverted repeat extending $27 \mathrm{bp}$. Examination of mig/CAT constructs with mutations in $\gamma R E-1$ revealed that the palindromic positions in the element were essential for activity. Consistent with its function as an enhancer, a single copy of $\boldsymbol{\gamma} R E-1$ conferred IFN- $\gamma$ inducibility to a heterologous (herpes simplex virus thymidine kinase) promoter. Exonuclease III protection assays demonstrated symmetrical protection of a mig promoter fragment centered about the $\gamma R E-1$ palindromic sequence. Using the gel electrophoretic mobility shift assay, we identified a factor $(\gamma R F-1)$ present in nuclear extracts prepared from IFN- $\gamma$-stimulated RAW 264.7 cells which binds to $\gamma$ RE-1. The activation of $\gamma R F-1$ occurred rapidly (within $1 \mathrm{~min}$ ) in response to IFN- $\gamma$ and was independent of protein synthesis. Similar to the expression of mig mRNA, the formation of $\gamma$ RF-1 was selectively induced by IFN- $\gamma$ and not IFN- $\alpha$. The regulation of gene expression through $\gamma \mathrm{RF}-1$ and $\gamma \mathrm{RE}-1$ may explain the preferential activation of a subset of interferon-inducible genes by IFN- $\boldsymbol{\gamma}$.

The interferons (IFNs) are an important group of cytokines which share many biologic effects including the induction of antiviral activity, the regulation of cell growth and differentiation, and the modulation of the immune response $(20,30)$. Similar to other cytokines, the IFNs induce many of their biologic effects through the regulation of specific RNA and protein expression in the responding cells (31). Therefore, knowledge of the ways in which the IFNs regulate gene transcription is essential to our understanding of the basic mechanisms of their action.

Although type I (IFN- $\alpha$ and IFN- $\beta$ ) and type II (IFN- $\gamma$ ) IFNs bind to different cell surface receptors, they induce the expression of an overlapping set of genes $(4,13,31)$. The study of genes activated by both type I and II interferons has led to the identification of two well-characterized promoter elements, namely, the interferon-stimulated response element (ISRE) $(15,24)$ and the IFN- $\gamma$ activation site (GAS) (26). The ISRE is present in the promoter regions of a number of IFN-stimulated genes including the class I major histocompatibility complex genes, guanylate-binding protein, and metallothionein II $(15,24,26)$. The transcription factor which binds to the ISRE is a multimeric complex known as ISGF3 and has been extensively characterized by several groups of investigators $(1,6,16,22,25)$. The GAS element was identified as a region overlapping with an ISRE sequence in the guanylate-binding protein promoter and contributing to the responsiveness of the guanylate-binding protein gene to IFN- $\gamma$. It was subsequently found to bind

* Corresponding author. Mailing address: Division of Rheumatology and Clinical Immunology, University of Pittsburgh School of Medicine, 985 Scaife Hall, Pittsburgh, PA 15261. Phone: (412) 624-9028. Fax: (412) 624-4901. factors (IFN- $\gamma$ activation factor [GAF] and IFN- $\alpha$ activation factor $[A A F]$ ) activated by both types of IFNs $(7,8)$.

It has long been recognized that IFN- $\gamma$ induces the expression of unique mRNAs and proteins not induced by IFN- $\alpha$ and IFN- $\beta(21,38)$. Our understanding of the regulation of the genes encoding these unique mRNAs and proteins has lagged behind the advances described above for genes induced by both type I and II IFNs. This is in part because only relatively recently have the cDNA and genomic clones corresponding to this subset of IFN- $\gamma$-inducible genes been obtained $(5,11,12,29,43)$. For some time, investigation into the mechanism by which IFN- $\gamma$ preferentially activates gene transcription has focused primarily on the promoters of the class II major histocompatibility complex genes $(2,3,9,14$, $32,44)$. This has proven to be a complicated system with evidence for cell-type-specific, constitutive, and cytokineregulated expression. Work in several laboratories has defined a complex array of cis elements $(\mathrm{H}, \mathrm{W}, \mathrm{X}, \mathrm{Y}$, and $\mathrm{Z}$ boxes and $\gamma$-IRE) within the class II major histocompatibility complex promoters which bind constitutive and induced transcription factors, and interactions between these multiple elements are reported to be necessary for regulation by IFN- $\gamma(9,14,44)$. Whether these elements will prove to be important in the regulation of other genes by IFN- $\gamma$ remains to be determined.

More recently, additional IFN- $\gamma$-responsive sequences have been identified in the promoters of genes rapidly induced by IFN- $\gamma(29,37,41)$. Sims et al. (37) found that an element (IR1) consisting of an imperfect inverted repeat of two GAAANN motifs, which are also present in the ISRE (24), is essential for responsiveness of the interferon regulatory factor 1 (IRF-1) gene promoter to IFN (37). In addition, they identified a DNA-binding factor (IRFi) which is acti- 
vated by IFN- $\gamma$ and to a lesser extent by IFN- $\alpha$. IRFi binds to IR1, but its binding is not inhibited by the ISRE (37). Similarly, analysis of the promoter region of the gene encoding the high-affinity Fc receptor for immunoglobulin G (Fc $\gamma \mathrm{RI}$ ) has revealed an element (GRR) which is necessary for IFN- $\boldsymbol{\gamma}$-inducible expression and capable of conferring IFN- $\gamma$ responsiveness to a heterologous promoter (29). Interestingly, GRR contains a motif shared with the GAS element, and it has been shown that the two electrophoretically distinct GRR-protein complexes (FcRFy1 and FcRF $\gamma 2$ ) observed by gel shift assay contain the p91 component of GAF and at least one additional protein responsible for DNA binding $(19,23)$.

The mig (monokine induced by IFN- $\gamma$ ) cDNA was isolated by differential screening of a cDNA library prepared from lymphokine-stimulated RAW 264.7 cells (mouse macrophage-like cell line) and encodes a member of the platelet factor 4-interleukin-8 family of low-molecular-weight cytokines (12). Transcription of the mig gene occurs specifically in response to IFN- $\gamma$ (but not type I IFN) and occurs in the absence of new-protein synthesis (41). These properties make it a particularly suitable system for the examination of the IFN- $\gamma$-specific transcriptional control. In a previous report we demonstrated that an 88-bp mig promoter fragment was capable of conferring IFN- $\gamma$ inducibility to a heterologous promoter (41). We now present further analysis of mig gene regulation, including the identification of a novel palindromic cis element responsive to IFN- $\gamma$, and preliminary characterization of the IFN- $\gamma$-activated transcription factor which binds to this element.

\section{MATERIALS AND METHODS}

Cells and transient transfections. The RAW 264.7 cell line was obtained from the American Type Culture Collection and was maintained in RPMI 1640 medium supplemented with $10 \%$ fetal bovine serum and $2 \mathrm{mM}$ L-glutamine. Transient transfection of RAW 264.7 cells was performed by a modification of the DEAE-dextran method as described previously (41). Briefly, cells were plated at $2 \times 10^{6}$ per 60-mm tissue culture dish 2 days prior to transfection. After being washed twice with $3 \mathrm{ml}$ of OPTIMEM (GIBCO/Life Technologies), the cells were incubated with the DNA/ DEAE-dextran solution (4 $\mu \mathrm{g}$ of plasmid DNA, $250 \mu \mathrm{g}$ of DEAE-dextran per $\mathrm{ml}$ ) in OPTIMEM for $1 \mathrm{~h}$; this was followed by the addition of chloroquine (final concentration, $100 \mu \mathrm{M}$ ) and further incubation for 1.5 to $2 \mathrm{~h}$. The DNA/ DEAE-dextran solution was then aspirated, and the cells were treated with $10 \%$ dimethyl sulfoxide in $2 \mathrm{ml}$ of phosphate-buffered saline (PBS) for $1 \mathrm{~min}$ and given three washes with $5 \mathrm{ml}$ of PBS. Culture medium $(5 \mathrm{ml})$ was added, and the dishes were incubated at $37^{\circ} \mathrm{C}$ for 18 to $20 \mathrm{~h}$. The contents of each dish were then scraped into $8 \mathrm{ml}$ of fresh culture medium and divided between two (or in some experiments three) $60-\mathrm{mm}$ culture dishes. After incubation for $2 \mathrm{~h}$ at $37^{\circ} \mathrm{C}$ to allow the cells to adhere, one dish from each transfection group received medium alone, one received recombinant murine IFN- $\gamma(1,000 \mathrm{U} / \mathrm{ml}$; GIBCO/Life Technologies), and in some experiments a third dish received recombinant murine IFN- $\alpha(1,000 \mathrm{U} / \mathrm{ml}$; GIBCO/Life Technologies), as indicated. The cells were harvested for analysis of chloramphenicol acetyltransferase (CAT) expression after an 18- to 24-h period of stimulation.

Preparation of mig/CAT reporter constructs. A mig genomic fragment extending from position -1117 to +43 relative to the transcription start site was ligated into the
SmaI site of the promoterless CAT reporter plasmid pUMSVOCAT (33). By using available EcoRV and HindIII sites in the mig promoter (41), two plasmids, $\mathrm{p}(-704 /$ +43)CAT and $\mathrm{p}(-358 /+43) \mathrm{CAT}$ (also referred to as p119HIIICAT), containing major 5 ' deletions were prepared. A series of ' 5 ' deletion mutants was prepared from p119HIIICAT by using exonuclease III (Erase-a-Base; Promega). The inserts of the $3^{\prime}$ deletion mutants and the IFN- $\gamma$-responsive element ( $\gamma$ RE- 1$)$ point mutants were prepared by PCR, using as primers the oligonucleotides corresponding to the indicated mig genomic sequences (or mutant sequences) with the addition of either BamHI or BglII restriction sites at the $5^{\prime}$ ends of the oligonucleotides. After the PCRs, the products were digested with $B a m H I$ and $B g l I I$ and subjected to gel purification of the DNA fragments. The DNA fragments containing 3 ' deletions of the mig promoter were ligated into the BamHI site of pBLCAT2, which contains the herpes simplex virus thymidine kinase (tk) promoter upstream of the CAT gene (27). The DNA fragments containing point mutations in the $\gamma \mathrm{RE}-1$ sequence were ligated into pUMSVOCAT, which had been modified to contain a BglII site in place of the SmaI cloning site. Additional plasmids containing the $\gamma \mathrm{RE}-1$ sequence or the indicated duplications of the left and right halves of $\gamma$ RE- 1 were prepared by annealing complementary oligonucleotides and ligating them into the BamHI site of pBLCAT2. The sequences of the inserts were determined by the dideoxy chain termination method.

CAT assays. Preparation of cell lysates and determination of CAT activity were performed as described previously (17) with the modification that butyryl coenzyme A (Pharmacia) was used in lieu of acetyl coenzyme A. CAT activities were adjusted for differences in protein concentrations of the extracts. Relative CAT activity was determined by subtracting the value for mock-transfected cultures (arbitrarily set at a value of zero) and expressing the result as a percentage of the positive control plasmid (e.g., containing the indicated wild-type sequence or p119HIIICAT).

Nuclear and cytosol extracts. Nuclear and cytosol extracts were prepared according to the method of Dignam et al. (10) with the modifications that $0.1 \%$ Triton X-100 was included in all buffers and extracts were diluted 1:4 in buffer $D$ (storage buffer) to reduce the salt concentration rather than being dialyzed.

Exonuclease III protection assay. DNA fragments radiolabeled at the $5^{\prime}$ terminus of one strand and containing the mig genomic sequence from -235 to -148 were prepared by first radiolabeling the oligonucleotide primers 5'-CGGGATCCA ATTTCTGCATGTTCTAC-3' and 5'-GAAGATCTCAGGT AGGAACTTTGCCT-3', which correspond to the mig promoter sequences from -235 to -218 and from -148 to -165 , respectively (to which have been added sequences for $B a m \mathrm{HI}$ and BglII sites for cloning purposes), with T4 polynucleotide kinase and $\left[{ }^{32} \mathrm{P}\right] \mathrm{ATP}(6,000 \mathrm{Ci} / \mathrm{mmol}$; New England Nuclear). Two PCRs (labeling either the upper or lower strand) were performed with the above primer pair (one radiolabeled and one unlabeled primer) and a mig genomic fragment $(-358$ to +43$)$ cloned into pBluescript as the template. After amplification for 25 cycles, the radiolabeled products were purified by ion-exchange chromatography (Qiagen). Exonuclease III protection was based on the method of $\mathrm{Wu}(42)$. The reaction mixtures contained $40 \mu \mathrm{g}$ of crude nuclear extracts, $2 \mu \mathrm{g}$ of denatured salmon sperm DNA, end-labeled DNA fragment $\left(3 \times 10^{4} \mathrm{cpm}\right)$, and binding buffer $(50 \mathrm{mM} \mathrm{KCl}, 0.5 \mathrm{mM}$ EDTA, $0.1 \%$ Triton X-100, 1.5 $\mathrm{mM} \mathrm{MgCl}_{2}, 2 \mathrm{mM}$ dithiothreitol, $12.5 \%$ glycerol, $10 \mathrm{mM}$ 
Tris- $\mathrm{HCl}$ [pH 7.5]) in a volume of $60 \mu \mathrm{l}$. After incubation for $20 \mathrm{~min}$ at $25^{\circ} \mathrm{C}$, exonuclease III (400 U; New England Biolabs) was added and digestion was allowed to proceed for $15 \mathrm{~min}$ at $25^{\circ} \mathrm{C}$. The reactions were terminated by the addition of $170 \mu$ l of chilled $\left(-60^{\circ} \mathrm{C}\right)$ stop solution $(20 \mu \mathrm{g}$ of tRNA per ml, $4.5 \mathrm{mM}$ EDTA, $0.9 \mathrm{M}$ ammonium acetate, $87 \%$ ethanol) and the samples were precipitated in a dry ice-ethanol bath for $15 \mathrm{~min}$. The precipitates were pelleted $\left(15,000 \times g\right.$ for $15 \mathrm{~min}$ at $\left.4^{\circ} \mathrm{C}\right)$, washed twice with $70 \%$ ethanol, dried for $15 \mathrm{~min}$ in a vacuum centrifuge, and dissolved in $10 \mu$ l of formamide loading buffer. After being heated at $90^{\circ} \mathrm{C}$ for $5 \mathrm{~min}, 5 \mu \mathrm{l}$ of each sample was loaded on a $6 \%$ acrylamide-7.8 $\mathrm{M}$ urea sequencing gel. Thermocycle sequencing reaction mixtures (CircumVent; New England Biolabs) with the same oligonucleotides and template used in preparation of the radiolabeled fragments (see above) were loaded in adjacent lanes to identify the termini of the protected fragments.

Gel electrophoretic mobility shift assay. Double-stranded oligonucleotides containing the $\gamma \mathrm{RE}-1$ sequence $(-200$ to $-167)$ of the mig promoter or the GAS sequence $(-126$ to $-101)$ of the guanylate-binding protein promoter $(26)$ were radiolabeled with $\left.{ }^{32} \mathrm{P}\right] \mathrm{dGTP}$ and $\left[{ }^{32} \mathrm{P}\right] \mathrm{dATP}$ (both at 6,000 $\mathrm{Ci} / \mathrm{mmol}$ ) by using the Klenow fragment of DNA polymerase I. Binding reaction mixtures $(25 \mu \mathrm{l})$ contained the indicated amount of nuclear or cytosol extract, $5 \mathrm{fmol}$ (approximately $10^{5} \mathrm{cpm}$ ) of radiolabeled DNA fragment, and $2 \mu \mathrm{g}$ of denatured salmon sperm DNA in binding buffer. Reaction mixtures were incubated for $20 \mathrm{~min}$ at room temperature, 5 $\mu \mathrm{l}$ of $0.1 \%$ bromphenol blue in binding buffer was then added, and the mixture was immediately loaded on a $6 \%$ polyacrylamide gel. Electrophoresis was performed in $0.25 \times$ TBE buffer (TBE buffer is $89 \mathrm{mM}$ Tris base, $89 \mathrm{mM}$ boric acid, and $2 \mathrm{mM}$ EDTA [pH 8]) at $175 \mathrm{~V}$ with buffer recirculation. Where indicated, unlabeled double-stranded oligonucleotides (specific competitors) were added to the binding reaction mixture before the addition of radiolabeled fragment.

\section{RESULTS}

Mapping the $5^{\prime}$ borders of IFN- $\gamma$-responsive elements within the mig promoter. To define the region(s) of the mig gene responsible for transcriptional activation by IFN- $\gamma$, we prepared a series of constructs containing $5^{\prime}$ deletions of the mig promoter coupled to the CAT reporter gene in the plasmid pUMSVOCAT. These constructs were analyzed for IFN- $\gamma$ inducibility in transient-transfection experiments with the mouse macrophage cell line RAW 264.7. Transfected cultures were treated with medium alone or medium supplemented with IFN- $\gamma(1,000 \mathrm{U} / \mathrm{ml})$ for 18 to $24 \mathrm{~h}$, and then the cells were harvested and cell extracts were prepared for analysis of CAT activity. The results of these transfections with constructs containing successive $5^{\prime}$ deletions of the mig promoter region are shown in Fig. 1A. The basal activity of these constructs was extremely low, with a mean percent conversion of $0.07 \%$, which was at least in part due to the low background of plasmid pUMSVOCAT (33). The results are expressed as IFN- $\boldsymbol{\gamma}$-inducible CAT activity relative to plasmid p119HIIICAT $(100 \%)$, which contains the mig genomic sequence from -358 to +43 . This plasmid was included in the transfection experiments as a positive control and internal standard. As shown in Fig. 1A, there was marked induction of CAT expression ( 250 - to 1,000 -fold) by IFN- $\gamma$ in cells transfected with plasmids containing the deletions spanning the region from -1117 to -198 . Consis-
A

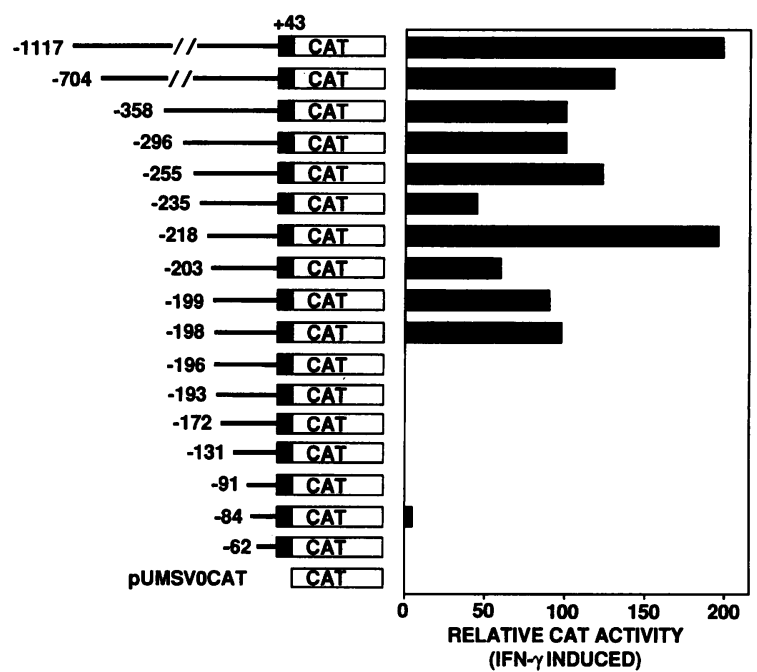

B

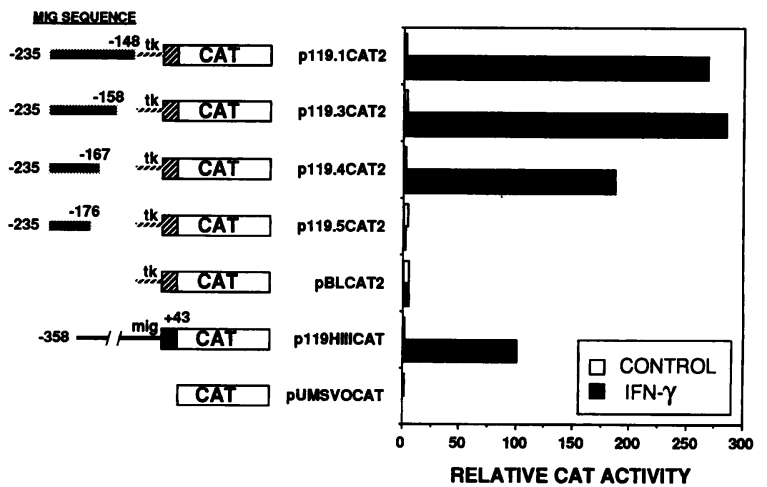

FIG. 1. Mapping enhancer elements in the 5' regulatory region of the mig gene. (A) IFN- $\gamma$-induced CAT activity in RAW 264.7 cells transiently transfected with plasmids containing $5^{\prime}$ deletions of mig promoter region upstream of the CAT reporter gene in the plasmid pUMSV0CAT. The data are the composite from eight experiments ( $n \geq 4$ for each plasmid) and are expressed relative to the activity of plasmid p119HIIICAT (set equal to 100) which contains the mig sequence from -358 to +43 . Shown are the values for relative CAT activity in IFN- $\gamma$-treated cultures. Control (unstimulated) samples demonstrated uniformly minimal basal activity, with a mean conversion of $0.07 \%$ and relative activity of $0.19(n=69)$. (B) CAT activity of RAW 264.7 cells transfected with plasmids containing $3^{\prime}$ deletions of the mig promoter region upstream of the herpes simplex virus tk promoter in the vector pBLCAT2. The data are the means of results from three experiments performed in duplicate and are expressed as relative CAT activity with the value for plasmid p119HIIICAT set equal to 100 .

tent with the selective stimulation of mig mRNA by IFN- $\gamma$ and not IFN- $\alpha$, the activation of these constructs was totally dependent on treatment with IFN- $\gamma(40,41)$. Although there was some variability (approximately two- to fourfold) in IFN- $\gamma$-inducible CAT expression among the $5^{\prime}$ deletion mutants with mutations spanning the region from -1117 to -198 , possibly because of the influence of minor regulatory elements, total loss of activity was observed in extracts from cells transfected with the construct containing the mig gene fragment from -196 to +43 . The analysis of these deletion mutants, therefore, mapped the $5^{\prime}$ border of a potent IFN- 
$\gamma$-responsive element to within 2 nucleotides $(-198$ to $-197)$.

Further deletions revealed a second IFN- $\gamma$-responsive element in the region of position -84. CAT activity in extracts from RAW 264.7 cells transfected with the construct containing the mig sequence from -84 to +43 was stimulated approximately 40 -fold by IFN $-\gamma$. In contrast, the CAT activity was not induced by treatment with $1,000 \mathrm{U}$ of IFN- $\alpha$ per $\mathrm{ml}(40)$. The absence of activity of this element in constructs containing adjacent $5^{\prime}$ sequence suggests the presence of an overlapping negative regulatory element. In this regard, it is interesting that the sequence immediately upstream of position -84 (41) has a high degree of homology (12-of-15 match with the consensus) to the ISRE, a cis element previously shown to be important in the positive regulation of IFN-inducible genes $(15,24)$ and recently found to suppress IFN-inducible transcription through the binding of the interferon consensus sequence-binding protein (28).

Identification of the $3^{\prime}$ border of the $\gamma$ RE-1. Because of the relative potency of the two positive regulatory regions identified by $5^{\prime}$ deletion mutants, we focused our efforts on characterizing the element(s) whose $5^{\prime}$ border was defined as position -198 or $-197(\gamma$ RE-1). Taking advantage of the fact that a single copy of the mig genomic fragment extending from positions -235 to -148 conferred IFN- $\gamma$ responsiveness to a heterologous (tk) promoter (41), we used PCR to prepare a series of DNA fragments containing various amounts of mig genomic sequence $3^{\prime}$ of position -198 and inserted them upstream of the tk promoter in the CAT reporter plasmid pBLCAT2 (27). Shown in Fig. 1B are the results of experiments in which these $3^{\prime}$ deletion mutants were tested for IFN- $\gamma$ inducibility by transient transfection of RAW 264.7 cells. Similar to the marked responsiveness of the constructs containing the homologous mig promoter region, the CAT activity in extracts from cells transfected with plasmids p119.1CAT2, p119.3CAT2, and p119.4CAT2, containing one copy of the indicated mig genomic sequence, was induced more than 100 -fold by IFN- $\gamma$. This activity was independent of orientation of the inserted mig genomic fragments $(40,41)$. In contrast, there was no stimulation of CAT activity in cells transfected with the deletion mutant p119.5CAT2, which contained the mig sequence from -235 to -176 .

On the basis of the data from the $5^{\prime}$ and $3^{\prime}$ deletion mutants, it was predicted that the IFN- $\gamma$-responsive cis element $\gamma$ RE- 1 was present within the sequence from -198 to -167 . To confirm this prediction, a pair of complementary oligonucleotides corresponding to the mig genomic sequence from -200 to -167 (the $5^{\prime}$ border was extended to position -200 by the addition of a restriction site for cloning purposes) were annealed and ligated into pBLCAT2 upstream of the tk promoter. As shown in Fig. 2, treatment of RAW 264.7 cells transiently transfected with this construct, $\mathrm{p}(-200 /-167)$ CAT2, with IFN- $\gamma$ stimulated CAT activity markedly (over 25-fold). Similar to the activity of larger fragments containing the $\gamma \mathrm{RE}-1$ sequence (41), the IFN- $\gamma$ inducible activity of this construct was independent of the orientation of the inserted fragment (40).

Role of palindromic positions in $\boldsymbol{\gamma R E - 1 . ~ A ~ c o m p a r i s o n ~ o f ~}$ the $\gamma \mathrm{RE}-1$ sequence with the consensus sequences of previously reported IFN-responsive elements including the ISRE $(15,24)$, GAS (26), and $\gamma$-IRE (44) did not identify the presence of these elements, although partial homology (7of-15 match) to GAS was noted. Careful scrutiny, however, did reveal an imperfect palindrome extending from positions -198 to -172 . In order to address the importance of the

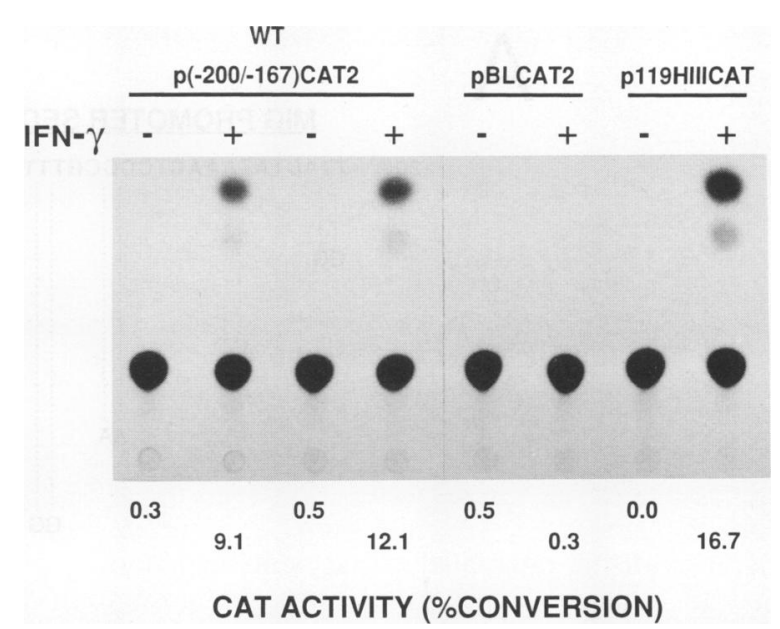

FIG. 2. A single copy of $\gamma$ RE-1 confers IFN- $\gamma$ inducibility to the herpes simplex virus tk promoter. Shown are the CAT activities of cell extracts prepared from RAW 264.7 cells transfected with the indicated plasmids. Cells were treated with medium alone or medium supplemented with IFN- $\gamma(1,000 \mathrm{U} / \mathrm{ml})$ for $23 \mathrm{~h}$ prior to harvest and determination of CAT activity. WT, wild type.

palindromic bases within $\gamma$ RE-1, DNA fragments containing the mig promoter sequence from -200 to +43 with various point mutations in each of the four palindromic segments or the central nonpalindromic region were generated by PCR mutagenesis. These fragments were inserted upstream of the CAT reporter gene in the vector pUMSV0CAT. The results of transient transfections of RAW 264.7 cells with these constructs are shown in Fig. 3A. Mutations in each of the four palindromic segments led to near-total loss of IFN- $\gamma$ inducible activity, whereas the construct with mutations in the central palindromic region retained approximately $25 \%$ of the activity of the wild-type sequence. These data supported the hypothesis that the palindromic nature of $\gamma \mathrm{RE}-1$ is important for its responsiveness to IFN- $\gamma$.

To evaluate this hypothesis further and to examine the importance of the central nonpalindromic spacer region, we prepared a series of CAT reporter constructs containing duplications of the $5^{\prime}$ or $3^{\prime}$ half of the imperfect palindrome present in $\gamma$ RE- 1 with various central regions (none, single, or double). These constructs were prepared by annealing complementary oligonucleotides corresponding to the mig promoter sequences indicated in Fig. 3B (with added $5^{\prime}$ GATC overhangs to permit cloning into a BamHI site) and ligating them into the Bam HI site of pBLCAT2. RAW 264.7 cells were transiently transfected with these constructs and analyzed for IFN- $\gamma$-inducible CAT expression. As shown in Fig. 3B, duplicating either half of $\gamma$ RE-1 resulted in a functional IFN- $\gamma$-responsive enhancer. The activity of the mutant element containing a duplication of the $3^{\prime}$ half of $\gamma \mathrm{RE}-1$ was significantly greater than that of the wild-type sequence, whereas the activity of the duplicated $5^{\prime}$ half of $\gamma \mathrm{RE}-1$ was consistently lower than that of the wild-type element. Deletion or duplication of the central nonpalindromic region of $\gamma$ RE-1 resulted in total loss of activity. These results suggest that the imperfect palindrome in $\gamma \mathrm{RE}-1$ may contain high-affinity ( $3^{\prime}$ half) and low-affinity ( $5^{\prime}$ half) binding sites, perhaps for a homodimeric transcription factor. The spacing of the two halves of the palindrome was critical for yRE-1 activity.

Identification of a $\boldsymbol{\gamma R E - 1 - b i n d i n g ~ p r o t e i n . ~ N u c l e a r ~ e x t r a c t s ~}$ 

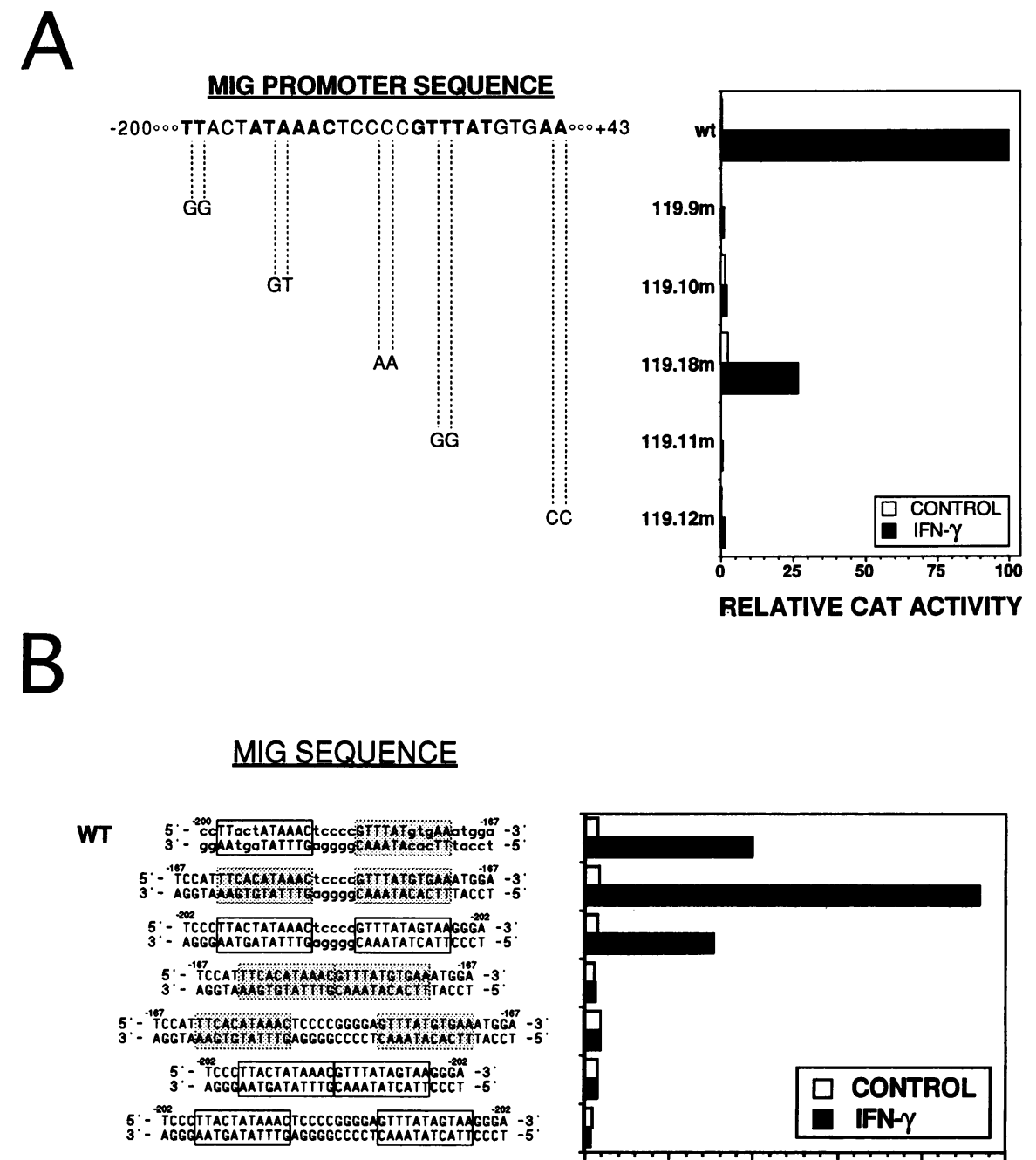


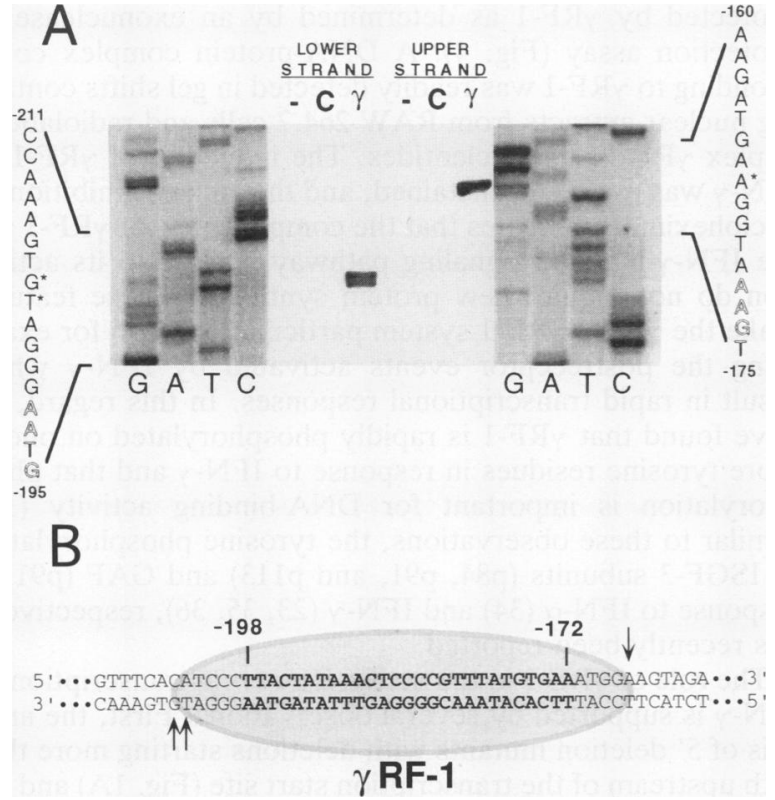

FIG. 4. Exonuclease protection assay. (A) DNA fragments end labeled on the $5^{\prime}$ end of either the upper or lower strand were incubated with nuclear extracts prepared from RAW 264.7 cells treated for $1 \mathrm{~h}$ with $500 \mathrm{U}$ of IFN- $\gamma$ per ml (lanes $\gamma$ ) or medium alone (lanes C), digested with exonuclease III, and resolved on a $6 \%$ denaturing polyacrylamide gel. Thermocycle sequencing reactions with the same radiolabeled primers as those used to prepare the end-labeled fragments were run adjacent to the exonuclease III reactions as markers. (B) Diagram illustrating the region protected from exonuclease III digestion. The arrows indicate the margins of the protected fragments (panel A), and the imperfect palindromic sequence is shown in boldface type. of $\gamma \mathrm{RF}-1$ in nuclear extracts from RAW 264.7 cells treated with IFN- $\gamma$ was very rapid, occurring within 1 min after stimulation (Fig. 5B), and $\gamma$ RF-1 activity persisted for at least $16 \mathrm{~h}$. At the earliest time point examined ( $1 \mathrm{~min}), \gamma \mathrm{RF}-1$ activity was equally distributed between cytosolic and nuclear fractions; however, after $5 \mathrm{~min}, \gamma \mathrm{RF}-1$ activity was predominantly nuclear in location (40). This observation, as well as the finding that $\mathrm{NaF}(10 \mathrm{mM})$ led to cytosolic accumulation of $\gamma \mathrm{RF}-1$ (40), supports the hypothesis that activation of $\gamma$ RF-1, similar to activation of ISGF3 and GAF by $\operatorname{IFN}-\alpha(6,22)$ and IFN- $\gamma(8)$, respectively, occurs in the cytosol and is followed by translocation of $\gamma \mathrm{RF}-1$ to the nucleus. Also, consistent with this hypothesis, we found that the activation of $\gamma$ RF- 1 by IFN- $\gamma$ does not require de novo protein synthesis as evidenced by the lack of inhibition by cycloheximide (Fig. 5B), indicating that $\gamma \mathrm{RF}-1$ is likely to be involved in the regulation of immediate-early-type genes responsive to IFN- $\gamma$.

Preferential activation of $\boldsymbol{\gamma R F}-1$ by IFN- $\boldsymbol{\gamma}$. There are now several examples of genes which are preferentially responsive to IFN- $\gamma$ and not type I (IFN- $\alpha / \beta)$ interferons $(5,11,12$, $29,43)$. Therefore, one of the most important issues regarding the role of $\gamma \mathrm{RF}-1$ in the regulation of gene transcription by IFN- $\gamma$ is whether $\gamma \mathrm{RF}-1$, similar to mig mRNA expression, demonstrated a differential response to the interferons. To address this issue, nuclear and cytosol extracts were made from RAW 264.7 cells stimulated for various times with $500 \mathrm{U}$ of IFN- $\gamma$ or IFN- $\alpha$ per ml. Gel shift assays with the nuclear extracts demonstrated that $\gamma$ RF-1 was induced by IFN- $\gamma$ but not by IFN- $\alpha$ (Fig. 6A). Cytosol fractions from the same experiment showed similar results (40), indicating that the failure to detect $\gamma \mathrm{RF}-1$ in the nuclear extracts from IFN- $\alpha$-treated cells was not due to a failure in nuclear translocation of the activated binding factor. The extracts from IFN- $\alpha$-treated cells did, however, contain AAF (Fig.
A

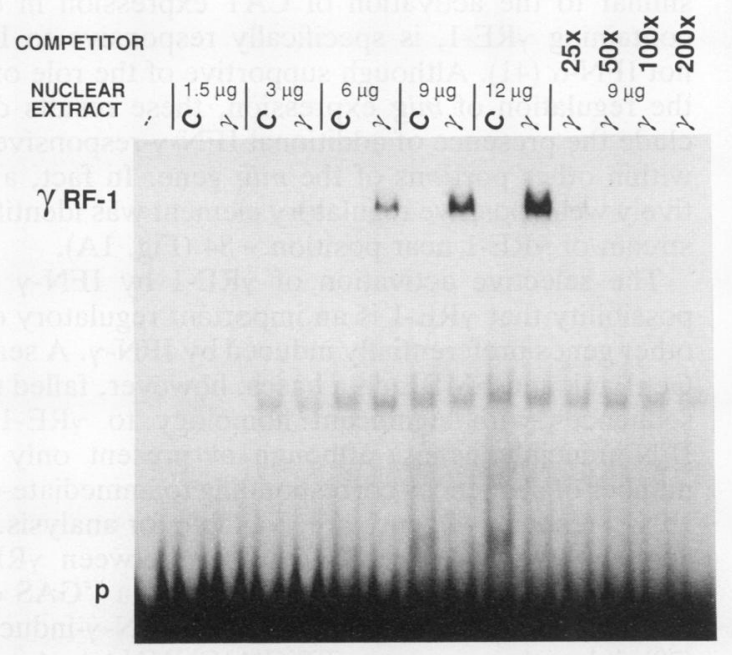

B

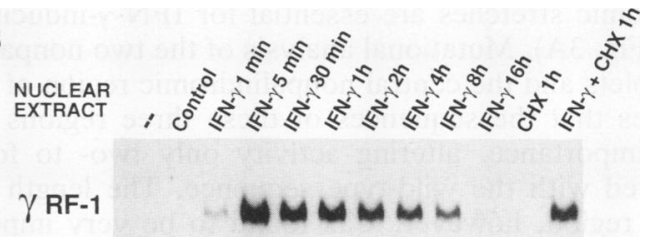

แแแแแแแแนแะ

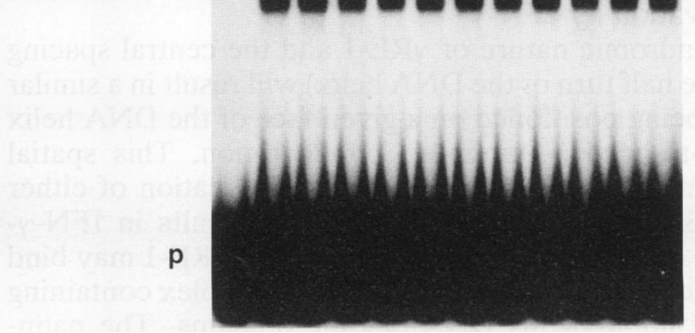

FIG. 5. (A) Detection of a $\gamma$ RE-1-binding protein $(\gamma R F-1)$ by gel electrophoretic mobility shift assay. Various amounts of nuclear extracts from unstimulated or IFN- $\gamma$-stimulated $(500 \mathrm{U} / \mathrm{ml}$ for $5 \mathrm{~min})$ RAW 264.7 cells were incubated with a radiolabeled duplex oligonucleotide corresponding to $\gamma$ RE-1 ( -200 to -167$)$, and the DNA-protein complexes were resolved by electrophoresis on a $6 \%$ native polyacrylamide gel. Where indicated, unlabeled fragment $(-200$ to -167$)$ was added as specific competitor. (B) Time course of $\gamma$ RF-1 activation. Nuclear extracts were prepared from RAW 264.7 cells treated with $500 \mathrm{U}$ of IFN- $\gamma$ per ml or medium alone in the presence or absence of cycloheximide $(10 \mu \mathrm{g} / \mathrm{ml})$ for the indicated times. These extracts were incubated with radiolabeled duplex oligonucleotide and analyzed as in panel A. p denotes free radiolabeled fragment (probe) in both panels. 
A

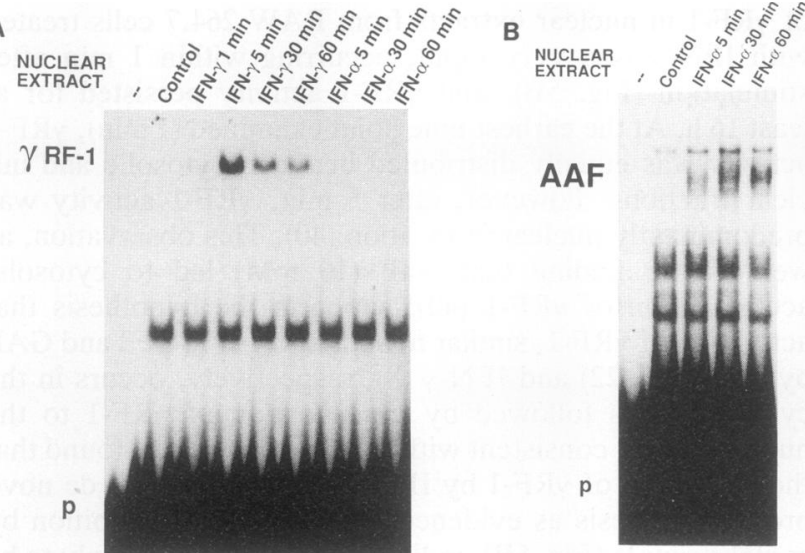

FIG. 6. Preferential activation of $\gamma$ RF-1 by IFN- $\gamma$. Nuclear extracts were prepared from RAW 264.7 cells treated for the indicated times with IFN- $\gamma(500 \mathrm{U} / \mathrm{ml})$, IFN- $\alpha(500 \mathrm{U} / \mathrm{ml})$, or medium alone (Control). Nuclear extracts were incubated with a radiolabeled duplex oligonucleotide corresponding to $\gamma \mathrm{RE}-1$ (A) or GAS (B), and the DNA-protein complexes were resolved by electrophoresis on a $6 \%$ native polyacrylamide gel. $\mathrm{p}$ denotes free radiolabeled fragment (probe) in both panels.

6B), an IFN- $\alpha$-inducible factor which binds to the GAS element (7).

\section{DISCUSSION}

The characterization of the mig promoter has led to the identification of a unique IFN- $\gamma$-responsive cis element, $\gamma \mathrm{RE}-1$. The $\gamma \mathrm{RE}-1$ sequence, defined functionally by $5^{\prime}$ and $3^{\prime}$ deletion analysis, contains the imperfect palindrome TTXXxATAAACXxxxxGTTTATxxxAA. Evaluation of a series of $\gamma$ RE-1 mutants showed that positions in all four palindromic stretches are essential for IFN- $\gamma$-inducible activity (Fig. 3A). Mutational analysis of the two nonpalindromic triplets and the central nonpalindromic region of $\gamma \mathrm{RE}-1$ indicates that the sequences of these three regions are of lesser importance, altering activity only two- to fourfold compared with the wild-type sequence. The length of the central region, however, was found to be very important, since mutant constructs containing 5-bp additions or deletions within the central nonpalindromic region had no IFN$\gamma$-inducible activity (Fig. 3B). Taken together, these data indicate that the presence of two half-sites and the proper spacing (5 bp) are essential for $\gamma \mathrm{RE}-1$-mediated transcriptional activation by IFN- $\gamma$.

The palindromic nature of $\gamma \mathrm{RE}-1$ and the central spacing of $5 \mathrm{bp}$ (one half turn of the DNA helix) will result in a similar sequence being positioned on a given face of the DNA helix in a head-to-head ( $\rightarrow \mathbf{x x x x x} \leftarrow)$ configuration. This spatial arrangement and the observation that duplication of either the $5^{\prime}$ or $3^{\prime}$ half of the $\gamma \mathrm{RE}-1$ sequence results in IFN- $\gamma$ responsive enhancers (Fig. 3B) suggest that $\gamma$ RE-1 may bind to a dimeric transcription factor $(\gamma \mathrm{RF}-1)$ complex containing two highly homologous DNA-binding domains. The palindromic motif is not a common feature of interferon-responsive enhancers (37). It is possible, therefore, that $\gamma \mathrm{RF}-1$ represents a new class of IFN- $\gamma$-activated transcription factors whose DNA-binding and transcription-enhancing properties are dependent on dimerization.

The $5^{\prime}$ and $3^{\prime}$ limits of $\gamma R E-1$ defined by analysis of deletion mutants (Fig. 1) correlate well with the sequence protected by $\gamma \mathrm{RF}-1$ as determined by an exonuclease III protection assay (Fig. 4). A DNA-protein complex corresponding to $\gamma \mathrm{RF}-1$ was readily detected in gel shifts containing nuclear extracts from RAW 264.7 cells and radiolabeled duplex $\gamma$ RE-1 oligonucleotides. The induction of $\gamma$ RF- 1 by IFN- $\gamma$ was rapid and sustained, and the lack of inhibition by cycloheximide indicates that the component(s) of $\gamma \mathrm{RF}-1$ and the IFN- $\gamma$-induced signaling pathway leading to its activation do not require new protein synthesis. These features make the $\gamma \mathrm{RE}-1 / \gamma \mathrm{RF}-1$ system particularly useful for examining the postreceptor events activated by IFN- $\gamma$ which result in rapid transcriptional responses. In this regard, we have found that $\gamma \mathrm{RF}-1$ is rapidly phosphorylated on one or more tyrosine residues in response to IFN- $\gamma$ and that phosphorylation is important for DNA-binding activity (18). Similar to these observations, the tyrosine phosphorylation of ISGF-3 subunits (p84, p91, and p113) and GAF (p91) in response to IFN- $\alpha(34)$ and IFN- $\gamma(23,35,36)$, respectively, has recently been reported.

The role of $\gamma \mathrm{RE}-1$ in the activation of mig transcription by IFN- $\gamma$ is supported by several observations. First, the analysis of 5 ' deletion mutants with deletions starting more than $1 \mathrm{~kb}$ upstream of the transcription start site (Fig. 1A) and the analysis of point mutations of $\gamma$ RE- 1 region in the context of homologous promoter elements (Fig. 3A) indicate that $\gamma \mathrm{RE}-1$ is the major IFN- $\gamma$-responsive cis regulatory element in the region of the mig promoter. Furthermore, a single copy of $\gamma \mathrm{RE}-1$ is capable of conferring marked IFN- $\gamma$ inducibility to a heterologous (herpes simplex virus tk) promoter. Also in support of the role of $\gamma \mathrm{RE}-1$ is the fact that the time course of $\gamma$ RF-1 activation (Fig. 5B) precedes and parallels the stimulation of mig mRNA expression in IFN$\gamma$-treated RAW 264.7 cells (12). In addition, treatment of RAW 264.7 cells with cycloheximide inhibits neither IFN- $\gamma$ induced mig transcription (41) nor the activation of $\gamma \mathrm{RF}-1$, indicating that both are independent of new protein synthesis. Finally, mig mRNA expression in RAW 264.7 cells, similar to the activation of CAT expression in constructs containing $\gamma \mathrm{RE}-1$, is specifically responsive to IFN- $\gamma$ and not IFN- $\alpha$ (41). Although supportive of the role of $\gamma$ RE-1 in the regulation of mig expression, these results do not exclude the presence of additional IFN- $\gamma$-responsive elements within other portions of the mig gene. In fact, a comparatively weak positive regulatory element was identified downstream of $\gamma$ RE-1 near position -84 (Fig. 1A).

The selective activation of $\gamma$ RE- 1 by IFN- $\gamma$ raises the possibility that $\gamma \mathrm{RE}-1$ is an important regulatory element in other genes preferentially induced by IFN- $\gamma$. A search of the GenBank and EMBL data bases, however, failed to identify sequences with significant homology to $\gamma \mathrm{RE}-1$ in other IFN-inducible genes, although at present only a limited number of sequences corresponding to immediate-early-type IFN- $\gamma$-responsive genes are available for analysis. As noted above, there is a partial homology between $\gamma \mathrm{RE}-1$ and a portion of the GAS element. Recently, a "GAS core site" has been identified by comparison of IFN- $\gamma$-inducible genes (29); it has the consensus TT(C/A)CNNNAA. A comparison of this sequence with $\gamma \mathrm{RE}-1$ reveals homology to both halves of the $\gamma \mathrm{RE}-1$ imperfect palindrome. At present the significance of this homology is uncertain. As shown in Fig. 6, the GAS sequence binds a factor (AAF) present in nuclear extracts from IFN- $\alpha$-treated RAW 264.7 cells, whereas $\gamma$ RE-1 does not. Furthermore, mutations in either half of the $\gamma$ RE-1 palindromic region abolish IFN- $\gamma$-inducible activity, although they leave one GAS core site intact (Fig. 3A). In addition, we have found that the time courses of $\gamma \mathrm{RF}-1$ and 
GAF activation by IFN- $\gamma$ are similar in RAW 264.7 cells but differ by several hours in HeLa cells (18). We are currently further investigating the potential relationship between these elements and their respective binding factors.

Since the mig mRNA was originally identified in cells of the macrophage-monocyte lineage $(12,13)$, another possible role for $\gamma$ RE-1 could be to regulate the tissue-specific expression of genes by IFN- $\gamma$. Arguing against this hypothesis, however, is the finding that $\gamma \mathrm{RF}-1$ is present in a wide variety of cell types after stimulation with IFN- $\gamma$, including mouse and human myeloid cells (RAW 264.7, human peripheral blood monocytes, THP-1, U937, and HL-60), human epidermoid carcinoma cell lines (HeLa and A431), human fibroblasts (MRC-5 and primary dermal fibroblasts), a mouse B-lymphoma cell line (X16C8.5), a human melanoma cell line (Hs 294T), and the Hep-G2 human hepatoma cell line (40). Whether $\gamma \mathrm{RE}-1$ and $\gamma \mathrm{RF}-1$ are involved in the regulation of a specific subset of cellular responses to IFN- $\gamma$ (e.g., induction of antiviral activity or inhibition of cell growth) in these varied cell types awaits further identification of the IFN- $\gamma$-responsive genes containing this new cis element.

\section{ACKNOWLEDGMENTS}

We thank J. Farber, H. Shin, and D. Nathans for their thoughtful advice; D. Honig and J. Gilmer for their excellent technical assistance; C. Feghali for her critical reading of the manuscript; and B. Knasko for her assistance in preparation of the manuscript.

This work was supported by Public Health Service grant CA55333 from the National Cancer Institute and an Arthritis Investigator Award from the Arthritis Foundation.

\section{REFERENCES}

1. Bandyopadhyay, S. K., D. V. R. Kalvakolanu, and G. C. Sen. 1990. Gene induction by interferons: functional complementation between trans-acting factors induced by alpha interferon and gamma interferon. Mol. Cell. Biol. 10:5055-5063.

2. Basta, P. V., P. A. Sherman, and J. P.-Y. Ting. 1987. Identification of an interferon- $\gamma$ response region $5^{\prime}$ of the human histocompatibility leukocyte antigen DR $\alpha$ chain gene which is active in human glioblastoma multiforme lines. J. Immunol. 138:1275-1280.

3. Collins, T., A. J. Korman, C. T. Wake, J. M. Boss, D. J. Kappes, W. Fiers, K. A. Ault, M. A. Gimbrone, Jr., J. L. Strominger, and J. S. Pober. 1984. Immune interferon activates multiple class II major histocompatibility complex genes and the associated invariant chain gene in human endothelial cells and dermal fibroblasts. Proc. Natl. Acad. Sci. USA 81:4917-4921.

4. Colonno, R. J., and R. H. L. Pang. 1982. Induction of unique mRNAs by human interferons. J. Biol. Chem. 257:9234-9237.

5. Dai, W., and S. L. Gupta. 1990. Regulation of indoleamine 2,3-dioxygenase gene expression in human fibroblasts by interferon- $\gamma$. J. Biol. Chem. 265:19871-19877.

6. Dale, T. C., A. M. A. Imam, I. M. Kerr, and G. R. Stark. 1989. Rapid activation by interferon $\alpha$ of a latent DNA-binding protein present in the cytoplasm of untreated cells. Proc. Natl. Acad. Sci. USA 86:1203-1207.

7. Decker, T., D. J. Lew, and J. E. Darnell, Jr. 1991. Two distinct alpha-interferon-dependent signal transduction pathways may contribute to activation of transcription of the guanylate-binding protein gene. Mol. Cell. Biol. 11:5147-5153.

8. Decker, T., D. J. Lew, J. Mirkovitch, and J. E. Darnell, Jr. 1991. Cytoplasmic activation of GAF, an IFN- $\gamma$-regulated DNAbinding factor. EMBO J. 10:927-932.

9. Dedrick, R. L., and P. F. Jones. 1990 . Sequence elements required for activity of a murine major histocompatibility complex class II promoter bind common and cell-type-specific nuclear factors. Mol. Cell. Biol. 10:593-604.

10. Dignam, J. D., R. M. Lebovitz, and R. G. Roeder. 1983. Accurate transcription initiation by RNA polymerase II in a soluble extract from isolated mammalian nuclei. Nucleic Acids
Res. 11:1475-1489.

11. Fan, X., G. R. Stark, and B. R. Bloom. 1989. Molecular cloning of a gene selectively induced by gamma interferon from human macrophage cell line U937. Mol. Cell. Biol. 9:1922-1928.

12. Farber, J. M. 1990 . A macrophage mRNA selectively induced by $\gamma$-interferon encodes a member of the platelet factor 4 family of cytokines. Proc. Natl. Acad. Sci. USA 87:5238-5242.

13. Farber, J. M. 1992. A collection of mRNA species that are inducible in the RAW 264.7 mouse macrophage cell line by gamma interferon and other agents. Mol. Cell. Biol. 12:15351545.

14. Finn, P. W., C. J. Kara, J. Douhan III, T. T. Van, V. Folsom, and L. H. Glimcher. 1990. Interferon $\gamma$ regulates binding of two nuclear protein complexes in a macrophage cell line. Proc. Natl. Acad. Sci. USA 87:914-918.

15. Friedman, R. L., and G. R. Stark. 1985. $\alpha$-Interferon-induced transcription of HLA and metallothionein genes containing homologous upstream sequences. Nature (London) 314:637639.

16. Fu, X.-Y., D. S. Kessler, S. A. Veals, D. E. Levy, and J. E. Darnell, Jr. 1990. ISGF3, the transcriptional activator induced by interferon $\alpha$, consists of multiple interacting polypeptide chains. Proc. Natl. Acad. Sci. USA 87:8555-8559.

17. Gorman, C. M., L. F. Moffat, and B. H. Howard. 1982. Recombinant genomes which express chloramphenicol acetyltransferase in mammalian cells. Mol. Cell. Biol. 2:1044-1051.

18. Guyer, N. B., and T. M. Wright. Unpublished data.

19. Igarashi, K.-I., M. David, A. C. Larner, and D. S. Finbloom. 1993. In vitro activation of a transcription factor by gamma interferon requires a membrane-associated tyrosine kinase and is mimicked by vanadate. Mol. Cell. Biol. 13:3984-3989.

20. Ijzermans, J. N. M., and R. L. Marquet. 1989. Interferongamma: a review. Immunobiology 179:456-473.

21. Kelley, V. E., W. Fiers, and T. B. Strom. 1984. Cloned human interferon- $\gamma$, but not interferon- $\beta$ or $-\alpha$, induces expression of HLA-DR determinants by fetal monocytes and myeloid leukemic cell lines. J. Immunol. 132:240-245.

22. Kessler, D. S., S. A. Veals, X.-Y. Fu, and D. E. Levy. 1990 Interferon- $\alpha$ regulates nuclear translocation and DNA-binding affinity of ISGF3, a multimeric transcriptional activator. Genes Dev. 4:1753-1765.

23. Larner, A. C., M. David, G. M. Feldman, K.-I. Igarashi, R. H. Hackett, D. S. A. Webb, S. M. Sweitzer, E. F. Petricoin III, and D. S. Finbloom. 1993. Tyrosine phosphorylation of DNA binding proteins by multiple cytokines. Science 261:1730-1733.

24. Levy, D. E., D. S. Kessler, R. Pine, N. Reich, and J. E. Darnell, Jr. 1988. Interferon-induced nuclear factors that bind a shared promoter element correlate with positive and negative transcriptional control. Genes Dev. 2:383-393.

25. Levy, D. E., D. J. Lew, T. Decker, D. S. Kessler, and J. E. Darnell, Jr. 1990. Synergistic interaction between interferon- $\alpha$ and interferon- $\gamma$ through induced synthesis of one subunit of the transcription factor ISGF3. EMBO J. 9:1105-1111.

26. Lew, D. J., T. Decker, I. Strehlow, and J. E. Darnell. 1991. Overlapping elements in the guanylate-binding protein gene promoter mediate transcriptional induction by alpha and gamma interferons. Mol. Cell. Biol. 11:182-191.

27. Luckow, B., and G. Schütz. 1987. CAT constructions with multiple unique restriction sites for the functional analysis of eukaryotic promoters and regulatory elements. Nucleic Acids Res. 15:5490.

28. Nelson, N., M. S. Marks, P. H. Driggers, and K. Ozato. 1993. Interferon consensus sequence-binding protein, a member of the interferon regulatory factor family, suppresses interferoninduced gene transcription. Mol. Cell. Biol. 13:588-599.

29. Pearse, R. N., R. Feinman, and J. V. Ravetch. 1991. Characterization of the promoter of the human gene encoding the highaffinity IgG receptor: transcriptional induction by $\gamma$-interferon is mediated through common DNA response elements. Proc. Natl. Acad. Sci. USA 88:11305-11309.

30. Pestka, S., J. A. Langer, C. K. Zoon, and C. E. Samuel. 1989. Interferons and their actions. Annu. Rev. Biochem. 56:727-777.

31. Revel, M., and J. Chebath. 1986. Interferon-activated genes. 
Trends Biochem. Sci. 11:166-170.

32. Rosa, F. M., and M. Fellous. 1988. Regulation of HLA-DR gene by IFN- $\gamma$ transcriptional and post-transcriptional control. J. Immunol. 110:1660-1662.

33. Salier, J.-P., and K. Kurachi. 1989. A CAT vector with virtually no background: pUMSV0CAT. BioTechniques 7:30-31.

34. Schindler, C., K. Shuai, V. R. Prezioso, and J. E. Darnell, Jr. 1992. Interferon-dependent tyrosine phosphorylation of a latent cytoplasmic transcription factor. Science 257:809-813.

35. Shuai, K., C. Schindler, V. R. Prezioso, and J. E. Darnell, Jr. 1992. Activation of transcription by IFN- $\gamma$ : tyrosine phosphorylation of a 91-kD DNA binding protein. Science 258:18081812.

36. Shuai, K., G. Stark, I. M. Kerr, and J. E. Darnell, Jr. 1993. A single phosphotyrosine residue of Stat 91 required for gene activation by interferon- $\gamma$. Science 261:1744-1746.

37. Sims, S. H., Y. Cha, M. F. Romine, P.-Q. Gao, K. Gottlieb, and A. B. Deisseroth. 1993. A novel interferon-inducible domain: structural and functional analysis of the human interferon regulatory factor 1 gene promoter. Mol. Cell. Biol. 13:690-702.
38. Weil, J., C. J. Epstein, and L. B. Epstein. 1983. A unique set of polypeptides is induced by $\gamma$ interferon in addition to those induced in common with $\alpha$ and $\beta$ interferons. Nature (London) 301:437-439.

39. Wong, P., C. W. Severns, C. A. Feghali, and T. M. Wright. Unpublished data.

40. Wong, P., and T. M. Wright. Unpublished data.

41. Wright, T. M., and J. M. Farber. 1991. 5' regulatory region of a novel cytokine gene mediates selective activation by interferon ү. J. Exp. Med. 173:417-422.

42. Wu, C. 1985. An exonuclease protection assay reveals heat shock and TATA box DNA-binding proteins in crude nuclear extracts. Nature (London) 317:84-87.

43. Wynn, T. A., C. M. Nicolet, and D. M. Paulnock. 1991. Identification and characterization of a new gene family induced during macrophage activation. J. Immunol. 147:4384-4392.

44. Yang, Z., M. Sugawara, P. D. Ponath, L. Wessendorf, J. Banerji, Y. Li, and J. L. Strominger. 1990. Interferon $\gamma$ response region in the promoter of the human $D P A$ gene. Proc. Natl. Acad. Sci. USA 87:9226-9230. 